\title{
The Brain in Motion II Study: study protocol for a randomized controlled trial of an aerobic exercise intervention for older adults at increased risk of dementia
}

Renata L. Krüger ${ }^{1,2}$, Cameron M. Clark ${ }^{3}$ Adrienna M. Dyck ${ }^{1,2}$, Todd J. Anderson ${ }^{4,5}$, Fiona Clement ${ }^{6,7}$, Patrick J. Hanly ${ }^{2,8}$, Heather M. Hanson ${ }^{6,9}$, Michael D. Hill 2,6,10,11,12, David B. Hogan 2,6,7,9,11, Jayna Holroyd-Leduc ${ }^{2,6,7,9,11}$, R. Stewart Longman²,8, Meghan McDonough ${ }^{7,13}$, G. Bruce Pike 2,10,12,14, Jean M. Rawling ${ }^{15}$, Tolulope Sajobi ${ }^{2,6,7}$ and Marc J. Poulin ${ }^{1,2,5,7,10,13,16,17^{*}}$ (iD

\begin{abstract}
Background: There remains no effective intervention capable of reversing most cases of dementia. Current research is focused on prevention by addressing risk factors that are shared between cardiovascular disease and dementia (e.g., hypertension) before the cognitive, functional, and behavioural symptoms of dementia manifest. A promising preventive treatment is exercise. This study describes the methods of a randomized controlled trial (RCT) that assesses the effects of aerobic exercise and behavioural support interventions in older adults at increased risk of dementia due to genetic and/or cardiovascular risk factors. The specific aims are to determine the effect of aerobic exercise on cognitive performance, explore the biological mechanisms that influence cognitive performance after exercise training, and determine if changes in cerebrovascular physiology and function persist 1 year after a 6-month aerobic exercise intervention followed by a 1-year behavioural support programme (at 18 months).
\end{abstract}

\footnotetext{
* Correspondence: poulin@ucalgary.ca

'Department of Physiology \& Pharmacology, Cumming School of Medicine, University of Calgary, Calgary, Alberta T2N 4N1, Canada

${ }^{2}$ Hotchkiss Brain Institute, Cumming School of Medicine, University of Calgary, Calgary, Alberta T2N 4N1, Canada

Full list of author information is available at the end of the article
}

(c) The Author(s). 2021 Open Access This article is licensed under a Creative Commons Attribution 4.0 International License, which permits use, sharing, adaptation, distribution and reproduction in any medium or format, as long as you give appropriate credit to the original author(s) and the source, provide a link to the Creative Commons licence, and indicate if changes were made. The images or other third party material in this article are included in the article's Creative Commons licence, unless indicated otherwise in a credit line to the material. If material is not included in the article's Creative Commons licence and your intended use is not permitted by statutory regulation or exceeds the permitted use, you will need to obtain permission directly from the copyright holder. To view a copy of this licence, visit http://creativecommons.org/licenses/by/4.0/ The Creative Commons Public Domain Dedication waiver (http://creativecommons.org/publicdomain/zero/1.0/) applies to the data made available in this article, unless otherwise stated in a credit line to the data. 
Methods: We will recruit 264 participants (aged 50-80 years) at elevated risk of dementia. Participants will be randomly allocated into one of four treatment arms: (1) aerobic exercise and health behaviour support, (2) aerobic exercise and no health behaviour support, (3) stretching-toning and health behaviour support, and (4) stretchingtoning and no health behaviour support. The aerobic exercise intervention will consist of three supervised walking/ jogging sessions per week for 6 months, whereas the stretching-toning control intervention will consist of three supervised stretching-toning sessions per week also for 6 months. Following the exercise interventions, participants will receive either 1 year of ongoing telephone behavioural support or no telephone support. The primary aim is to determine the independent effect of aerobic exercise on a cognitive composite score in participants allocated to this intervention compared to participants allocated to the stretching-toning group. The secondary aims are to examine the effects of aerobic exercise on a number of secondary outcomes and determine whether aerobic exercise-related changes persist after a 1-year behavioural support programme (at 18 months).

Discussion: This study will address knowledge gaps regarding the underlying mechanisms of the pro-cognitive effects of exercise by examining the potential mediating factors, including cerebrovascular/physiological, neuroimaging, sleep, and genetic factors that will provide novel biologic evidence on how aerobic exercise can prevent declines in cognition with ageing.

Trial registration: ClinicalTrials.gov NCT03035851. Registered on 30 January 2017

Keywords: Alzheimer's disease, Behavioural support, Brain health, Cognitive function, Dementia, Physical activity, Sleep quality

\section{Background}

Life expectancy is projected to rise over the coming decades for most industrialized countries [1]. There are already more than 1 billion people worldwide aged 60 years or older [2]. Despite the increase in longevity, the number of years spent in good physical health (e.g,. no mobility, functional, and/or cognitive impairments) has remained unchanged over the past few years in Canada [3]. There are a growing number of older individuals with age-related normative cognitive decline as well as Alzheimer's disease and related dementias (ADRD). Recent estimates suggest that worldwide, $\sim 50$ million people currently have dementia, and by 2030 , this is predicted to increase to $\sim 82$ million [4]. In Canada, $~ 500$, 000 older adults are now living with dementia [5]. Almost $40 \%$ of Canadians over the age of 65 have some degree of cognitive impairment [5]. Their direct cost care was estimated to be $\$ 10.4$ billion CDN dollars in 2019 and are projected to climb to $\$ 16.6$ billion CDN by 2031 [5]. The personal costs of dementia and these alarming public health estimates are motivating efforts to identify lifestyle interventions that can slow the progression of ADRD. In addition to focusing on treatment, studies have been targeting the prevention of neurodegenerative diseases with the aim of mitigating, delaying, or preventing the onset of ADRD [6-10].

Exercise is a promising method to reduce the risk of dementia in both healthy older adults and those at elevated risk of ADRD due to cardiovascular risk factors [11]. The physiological benefits of exercise in older adults are clear in the research literature and include improved arterial compliance (i.e., the ability of a vessel to expand as needed), endothelial function, energy metabolism, sleep quality, and muscle mass/strength [12]. Exercise also promotes cardiovascular fitness by improving global vascular health, including increases in middle cerebral artery vasodilation responses and cerebral blood flow (CBF) [13]. These brain adaptations could play an important role in delaying the onset of ADRD as greater CBF may prevent and/or reduce the accumulation of amyloid $\beta$ in the brain, which is one of the main pathological hallmarks of AD [14]. Additionally, improved cerebral haemodynamics may help prevent or slow other conditions that act as risk factors for cognitive decline and ADRD, such as cardiovascular disease (CVD) and diabetes [15]. Although steady-state CBF normally declines with post-maturation ageing, chronic diseases like CVD, hypertension, and diabetes can accelerate agerelated CBF alterations and lead to disruption of neuronal homeostasis $[16,17]$.

Existing scientific literature suggests that high levels of physical activity can positively impact cognitive function in middle-aged (50-64 years) and older ( $>65$ years) individuals [18-24]. Sofi and colleagues (2011) examined 15 prospective cohort studies that collectively followed more than 30,000 healthy older adults over 1-12 years. Individuals who were more physically active before the follow-up period had a 38\% reduced risk of cognitive decline compared to those with a sedentary lifestyle at baseline [22]. Cross-sectional studies have found an association between higher levels of physical activity in older adults with both better performance on specific cognitive tasks $[23,25]$ and reduced risk of cognitive decline [24]. 
Evidence from neuroimaging studies also supports the positive effects of exercise on brain health. Exercise has been shown to reduce age-related atrophy in grey and white matter [26], decrease both brain [27] and hippocampal atrophy [28], and increase white matter integrity $[29,30]$. Animal models suggest changes in neurotrophic factors in response to exercise may be partially mediated by enhanced levels of brain-derived neurotrophic factor (BDNF) and insulin-like growth factor (IGF-1) in the hippocampus [31]. BDNF improves overall neural health by increasing brain vascularization, neurogenesis, and synaptic efficiency in the hippocampus [31]. As BDNF plays a role in memory formation, enhanced levels of BDNF in the brain may help prevent memory loss and cognitive decline with ageing [31].

The literature on the associations between exercise, cognition, and brain health in older individuals primarily comprised epidemiological and observational studies $[22-24,29,30]$. These study designs only allow passive observation of events and are prone to selection, information, and confounding bias compared to RCTs and cannot be used to determine causality. The few RCTs investigating the relationship between exercise, cognition, and brain health have found, however, contradictory results [12, 32-34]. Possible explanations for the conflicting literature include sub-optimal study design and methods, such as small sample sizes, short exercise interventions, and inadequate tracking of participant adherence to prescribed exercise routines $[8,34,35]$. The methodological limitations of previous studies support the need for new well-designed RCTs to investigate the association between exercise and cognitive function in older adults [21].

Most prior RCTs of the effects of exercise did not include older participants at greater risk for ADRD due to CVD and/or genetic risk factors. Both CVD and ADRD share a number of risk factors (i.e., age, obesity, physical inactivity, smoking, elevated blood pressure, and high cholesterol) [36]. Older individuals with CVD risk factors may benefit more from exercise interventions in terms of their brain health and/or cognitive performance. People who have a family history of ADRD might also gain more from exercise programmes due to their genetic susceptibility from, for example, carrying the apolipoprotein $\mathrm{E}(A P O E)$ e4 allele. Individuals with at least one $A P O E$ e4 allele copy are at greater risk of developing $\mathrm{AD}$ [37].

Given the estimates of the burden of ADRD and the promising evidence of the benefits of exercise on cognitive health, we propose an RCT of aerobic exercise for individuals at increased risk of ADRD. This RCT will test the efficacy of a 6-month aerobic exercise intervention for the primary and secondary prevention of ADRD in older adults (50-80 years old). We will measure the cognitive and cerebrovascular outcomes, including vascular reactivity, vascular biomarkers, and changes in the brain structure and function using magnetic resonance imaging (MRI). A unique feature of this study is the inclusion of assessments linking vascular risk factors, neuroimaging markers, sleep, genetic risk, and cognitive health outcomes. The primary aim of this study is to determine the independent effect of aerobic exercise on a cognitive composite score, calculated as the average of ten cognitive tests (executive functioning, complex attention, processing speed, and verbal memory), between participants allocated in the aerobic vs stretching-toning groups. We hypothesize that participants randomized to the 6-month aerobic exercise intervention will score higher in the cognitive composite score following 6 months of training compared to participants allocated to a stretching-toning exercise intervention (control group). The secondary aims are to examine the comparative effects of aerobic exercise and stretching-toning on a number of secondary outcomes noted in the text and whether exercise-related changes persist 12 months after completion of the exercise intervention (i.e., at 18 months) and if a telephone-based behavioural support intervention leads to improved maintenance of the exercise-related benefits. We hypothesize that the effects of improved aerobic fitness and brain health (e.g., increase in resting $\mathrm{CBF}$ ) seen at 6 months with aerobic exercise will be at least partially maintained at the end of the follow-up period and that the telephone-based behavioural support intervention will be more effective in leading to persistent lifestyle changes and greater retention of any benefits that arise. To test these hypotheses, the participants will be randomly allocated into one of four treatment arms: (1) aerobic exercise and health behaviour support, (2) aerobic exercise and no health behaviour support, (3) stretching-toning and health behaviour support, and (4) stretching-toning and no health behaviour support.

\section{Methods}

The Brain in Motion II Study is an 18-month randomized controlled trial (RCT). It is open labelled with blinded evaluation superiority (aerobic exercise superior to stretching-toning) trial of four-armed parallel groups with a 1:1:1:1 allocation ratio. The trial utilizes a PROBE (Prospective, Randomized, Open with Blinded Endpoints) design [38]. The study protocol has been approved by the University of Calgary Conjoint Health Research Ethics Board (REB16-1199) and registered with ClinicalTrials.gov (NCT03035851). The RCT will be carried out according to the CONSORT and SPIRIT guidelines. 


\section{Participants}

A total of 264 male and female participants at elevated risk of ADRD between the ages of 50 and 80 will be recruited from the community in Calgary, Alberta, Canada, and surrounding areas via printed advertisements (e.g., posters and newspaper ads), media campaigns, and from physician offices through the University of Calgary Department of Family Medicine Teaching Clinics.

\section{Eligibility criteria}

A full listing of the inclusion and exclusion criteria is presented in Table 1 . This study will include inactive men and women 50-80 years of age at baseline who have subjective cognitive symptoms but no dementia and either one or more CVD risk factors for ADRD or a family history of ADRD. The study exclusion criteria are as follows: age less than 50 or greater than 80 years, current physical activity greater than 150 min per week of moderate-to-vigorous intensity physical activity, absence of CVD risk factors, presence of dementia (based on DSM-5 criteria) or severe cognitive deficits (Modified Telephone Interview for Cognitive Status (TICS-M) score $<20$ ), presence of a developmental handicap, terminal illness (life expectancy $<1$ year), non-fluency in verbal and written English, history of stroke, current participation in another clinical trial, comorbid medical or neurological illnesses (e.g., multiple sclerosis) that would confound cognitive assessments or make trial completion unlikely, and contraindication for the aerobic or stretching-toning interventions.

Inactivity will be assessed with a physical activity questionnaire [39] and defined as an engagement in $<150$ min/week of moderate-to-vigorous exercise [40]. The subjective cognitive symptoms, family history of dementia, CVD risk factors for ADRD, family history of ADRD, and current physical activity level will be assessed during a telephone interview. The aim is to recruit participants with either subjective cognitive decline or mild cognitive impairment who are at risk for progressive cognitive decline and dementia. This recruitment strategy is similar to the one used in a previous RCT that showed that exercise reduced the likelihood of cognitive decline [41], as measured by the Clinical Dementia Rating Scale [42]. That scale has been validated [43] and allows, with reasonable accuracy, the identification of individuals with mild cognitive impairment and those with very early AD. The presence of suspected dementia will be identified by medical history and cognitive impairment on the Telephone Interview for Cognitive Status (TICS-modified; score $\leq 20$ [44, 45];). The CVD risk factors for ADRD include a history of hypertension, diabetes mellitus, obesity (body mass index (BMI) $<40 \mathrm{~kg} / \mathrm{m}^{2}$ ), elevated cholesterol, current smoking, and coronary artery disease without recent (<5 years) symptoms. A family history of ADRD is defined as having a first-degree relative (parent, sibling, or child) who has been diagnosed with ADRD.

Following the telephone evaluation, the participants will be provided with a copy of the informed consent form to review-prior to the first one-site visit-as part of a "welcome package" and will also be asked to provide written permission to contact their family physician for medical clearance to participate in the study. The study coordinator will be responsible for obtaining the informed consent. Participants will then attend a 60-min on-site clinical laboratory eligibility screening session in which a written informed consent will be obtained by the study coordinator. During this visit, the participants will also complete the following assessments: the Brain Injury Screening Questionnaire (BISQ [46];), the Montreal Cognitive Assessment (MoCA [47]; the Memory

Table 1 Inclusion and exclusion criteria for the Brain in Motion // trial

\begin{tabular}{|c|c|}
\hline Inclusion criteria & Exclusion criteria \\
\hline $\begin{array}{l}\text { - Men and women aged } 50-80 \text { years (inclusive) } \\
\text { - Inactive (engagement < } 150 \text { min/week of moderate-to- } \\
\text { vigorous exercise) } \\
\text { - Subjective cognitive symptoms but no dementia }{ }^{a} \\
\text { - One or more CVD risk factors for ADRD or family history } \\
\text { of ADRD } \\
\text { - Female participants must be post-menopausal } \\
\text { - Able to walk independently outside, as well as up and } \\
\text { down the stairs of } 20 \text { steps }\end{array}$ & $\begin{array}{l}\text { - Presence of dementia (based on the DSM-5 criteria) or severe cognitive deficits (TICS-M } \\
\text { score }<20)^{a} \\
\text { - Absence of CVD risk factors or family history of ADRD } \\
\text { - Diagnosis of severe asthma or COPD (respiratory) } \\
\text { - Presence of a developmental handicap } \\
\text { - Terminal illness (life expectancy }<1 \text { year) } \\
\text { - Not fluent in verbal and written English } \\
\text { - History of stroke or serious cardiovascular condition } \\
\text { - Current participating in another trial } \\
\text { - Comorbid medical or neurological illness that would confound cognitive assessments } \\
\text { or make trial completion and unlikelyc } \\
\text { - Contraindication for exercise interventions }\end{array}$ \\
\hline
\end{tabular}

${ }^{a}$ Existing or suspected dementia will be identified by medical history, cognitive impairment on the Telephone Interview for Cognitive Status (TICS-modified; score $\leq 20$ ), or impaired Instrumental Activities of Daily Living (IADL) - a response of needs assistance or dependent due to cognitive impairments on any item on the Lawton scale

${ }^{\mathrm{b}}$ Cardiovascular disease (CVD) risk factors for Alzheimer's disease and related dementias (ADRD) include the history of hypertension, diabetes mellitus, obesity (body mass index (BMI) BMI $\geq 30$ but $<40 \mathrm{~kg} / \mathrm{m}^{2}$ ), elevated cholesterol, current smoking, and history of coronary artery disease without recent $(<5$ years) symptoms. Family history of ADRD is defined as having a first-degree relative (parent, sibling, or child) who has been diagnosed with ADRD

${ }^{C}$ E.g., persistent post-concussive symptoms or medication for psychological condition that would impact cognitive performance 
Assessment Clinic questionnaire (MAC-Q [48];), and the Physical Activity Readiness Questionnaire (PAR-Q+ [49, 50];). The BISQ is a screening tool used to identify a lifetime history of traumatic brain injury [46]. The MoCA score will be used to stratify the participants at baseline prior to their allocation into different experimental groups (see below). The MAC-Q is a validated measure of subjective memory complaints that has been previously used in healthy older and clinical/research populations [51]. Finally, the PAR-Q+ form will be used to determine the safety of exercise programme participation. This form will be completed by the participants and included in a fax sent to the participant's family physician requesting medical clearance to participate in the study. A certified exercise physiologist will review this questionnaire with participants prior to completing their exercise testing. Additionally, participants will be requested to complete a sociodemographic questionnaire and report on their use of medications and other therapies.

\section{Risks}

Risks of exercise include falls, musculoskeletal injuries, coronary heart disease events (myocardial infarct, acute coronary syndrome), and other side effects that are generally minor. Our previous experience with similar exercise interventions gives our team considerable expertise on the means to mitigate these types of health risks. Maximal cardiopulmonary testing will be conducted by certified exercise physiologists with a physician on-call and present for high-risk participants and appropriate emergency equipment available. A participant may be withdrawn from the study if a research procedure is judged to be potentially harmful or presents an unacceptable risk of injury to the participant. For example, participants could be withdrawn if they develop an abnormality (e.g., abnormal ECG suggesting an unstable cardiac issue, uncontrolled hypertension) that is judged by a physician associated with the study or the participant's attending physician to pose a risk to the participant if they continue in the study.

\section{Sample size}

Preliminary estimates of the effect sizes for improvement in overall cognition (cognitive composite score) with aerobic exercise training are based on the results of a previous study from our group, the Brain in Motion Study [52], that used similar active intervention and outcome. This study will recruit a total of 264 participants. This power calculation, which is based on a sample size calculation formula for a mixed model for repeated measures data with attrition [53], provides $80 \%$ power to detect 0.4 standard deviation between-group difference for an average repeated measurement correlation of 0.6 and three repeated measurements, taking $20 \%$ attrition into consideration (based on the Brain in Motion Study [52]; ) .

\section{Randomization}

This study will be a prospective open label with blinded evaluation (PROBE) trial and randomize the participants into one of the following four treatment arms:

(1) Aerobic exercise and health behaviour support: Participants will undergo aerobic exercise training for 6 months and will receive 1-year of individually tailored telephone support after the intervention.

(2) Aerobic exercise and no health behaviour support: Participants will undergo aerobic exercise training for 6 months and will not receive health behaviour support during the follow-up 1-year follow-up period (at 18 months).

(3) Stretching-toning and health behaviour support: Participants will undergo stretching-toning exercise training and will receive 1-year of individually tailored telephone support after the intervention.

(4) Stretching-toning and no health behaviour support: Participants will undergo stretching-toning exercise training and will not receive health behaviour support during the follow-up 1-year follow-up period (at 18 months).

Randomization sequence within blocks will be generated by computer using a random number generator. Randomization will be stratified by age (age > 65 vs $\leq 65$ years) and sex with blocked, simple randomization into each of 4 strata for each group of participants as they enter the study. Because enrolment occurs in complete groups of participants (rather than sequentially), randomization will be done in complete blocks such that randomness of allocation is completely preserved. Specifically, recruitment for each study site (e.g., University of Calgary, YMCA Calgary) will be done independently. Once the desired number of participants (8-15 participants) are recruited, baseline testing will be conducted. Participants will be then randomized (the random sequence will be generated by computer: REDCap randomization tool) and immediately start the exercise intervention. Randomized allocation will be completely masked to all study personnel, except the database programmer (study coordinator) who will not participate in any participant or protocol-related activities. Participants will receive a "welcome package" containing their allocation group during the baseline testing visits, in advance of the exercise programme starting date. 


\section{Blinding}

The nature of both the aerobic exercise intervention and health behaviour intervention precludes participants from being blinded to the group status; however, the researchers assessing any of the outcome variables will be blinded to participant group assignment to avoid bias in result interpretation. Since patients are not blinded, safety can be assessed in the context of the actual intervention, and, therefore, the research team will remain blinded to the group allocation.

\section{Study design}

Figure 1 displays an overview of the study design and participant flow through the trial. Once a participant is eligible to join the study, he or she will be asked to provide additional information during the 60 -min on-site eligibility screening session, including basic sociodemographic information (e.g., sex and gender), medical history (cardiovascular, respiratory, neurological), lifestyle habits (e.g., smoking history, physical activity levels), descriptive physical data (e.g., height, weight), level of education, current and past income and occupation, and current medications (prescribed, over-thecounter, and vitamins or supplements).

After the completion of the screening procedures, the participants will be randomly assigned to one of the four experimental groups. Following randomization, participants will undergo their first set of cerebrovascular/ physiological, neuroimaging, sleep, and cognitive factors and will complete several lifestyle and psychological questionnaires (see Table 2). This battery of assessments will be completed again following the 6-month intervention period and after a 1-year follow-up period.

\section{Exercise interventions}

Exercise sessions will be conducted in a small group (815 participants) by supervised by qualified trainers in community gyms and recreation centres (e.g., University of Calgary, YMCA Calgary). Costs associated with travelling will not be covered, but parking will be paid for all the exercise sessions. Trainers will have a background in kinesiology and/or certification as a personal trainer and will be trained with suitable emergency equipment and procedures in place. In the event that any of the assessments identify any concerns, the participant's family physician will be contacted to help in any further followup or the appropriate referral. There will be no compensation to those who suffer harm from trial participation. Participation is voluntary, and participants may withdraw at any time and not suffer any disadvantage or reprisal for withdrawing. The researcher may request a participant to withdraw from the study if a research procedure is judged to be potentially harmful to the participant.

Participants will be asked to maintain a minimum of $80 \%$ attendance rate at the exercise sessions. Participants who miss a supervised exercise session will be encouraged to complete the session independently and record the unsupervised session in a personal workout logbook (reviewed regularly by trainers). Participants are asked to

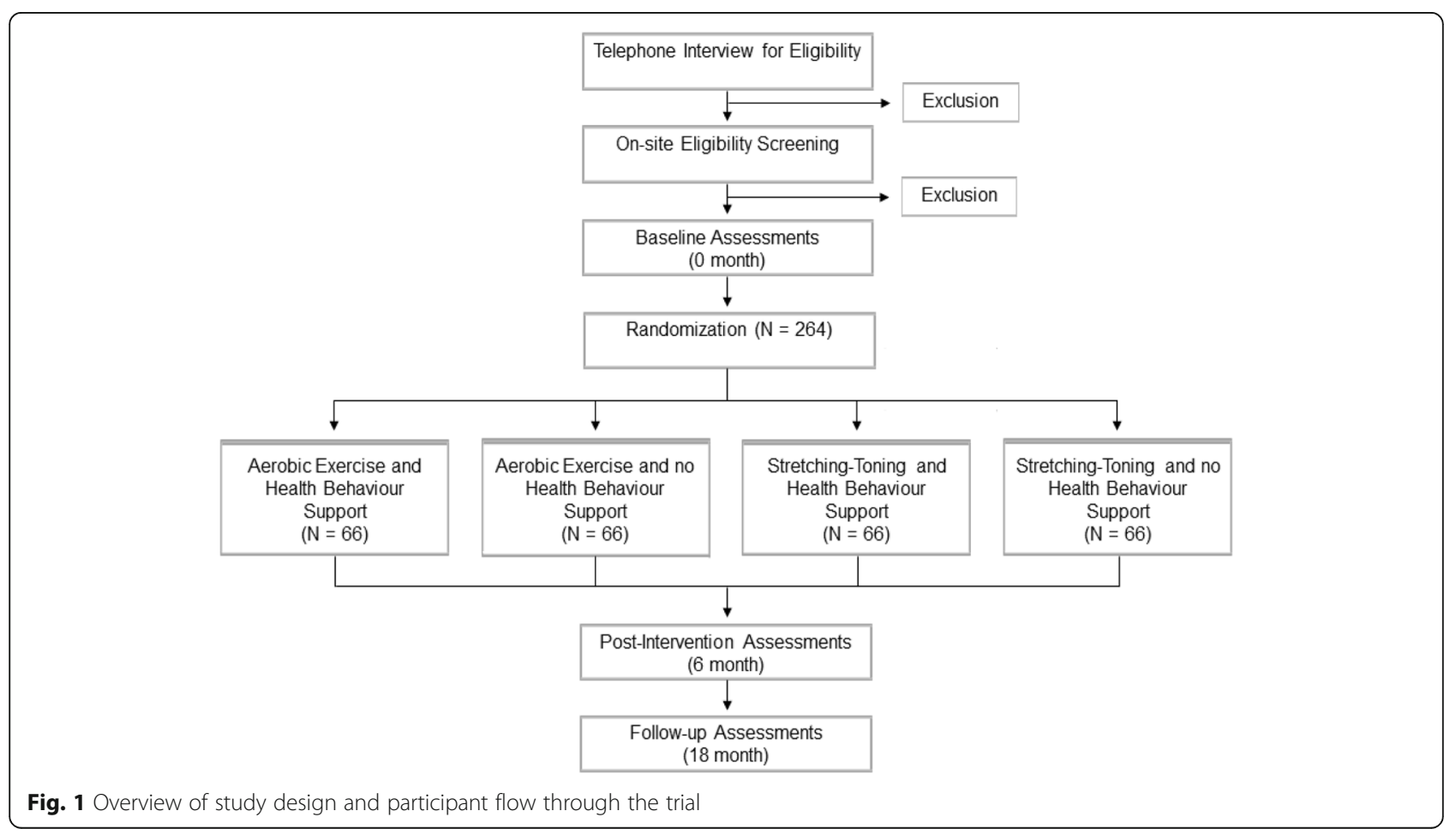


Table 2 Schedule of physiological, cognitive, psychological, and neuroimaging assessments for the Brain in Motion // trial

\begin{tabular}{lc}
\hline Assessment measure & $\begin{array}{c}\text { Scre } \\
\text { asse }\end{array}$ \\
\hline Screening & \\
Telephone Interview for Cognitive Status - Modified (TICS-m) & $\checkmark$ \\
Montreal Cognitive Assessment (MoCA) & $\checkmark$ \\
Medical history & $\checkmark$ \\
Demographics and health history & $\checkmark$ \\
Eligibility screening questionnaire & $\checkmark$ \\
Physical Activity Readiness Questionnaire (PAR-Q+) & $\checkmark$ \\
Brain Injury Screening Questionnaire (BISQ) & $\checkmark$ \\
Sociodemographic questionnaire & $\checkmark$ \\
Vital signs &
\end{tabular}

\section{Cognition}

Neuropsychological test battery

\section{Cerebral blood flow}

Transcranial Doppler ultrasound

\section{Maximal aerobic oxygen uptake}

Maximal aerobic capacity test

\section{Blood biomarkers}

Blood work

\section{Genetic risk factors}

\section{Risk/protective factors}

Global Physical Activity Questionnaire (GPAQ)

Diet History Questionnaire

Memory Assessment Clinic Questionnaire (MAC-Q)

Multiple Ability Self-Report Questionnaire (MASQ)

Lifetime Cognitive Activities Questionnaire

Current Cognitive Activities Questionnaire

Clinical Dementia Rating Scale (CDRS)

Lubben Social Network Scale

Family and Friend Support for Exercise

Physical activity-related autonomy support, persuasion, and pressure

Motivation for leisure time physical activity (BREQ-3)

Adult ADHD Self-Report Questionnaire (ASRS)

Hospital Anxiety and Depression Scale (HADS)

Geriatric Depression Scale (GDS)

Centres for Epidemiological Studies Depression Inventory

Beck Anxiety Inventory (BAI)

Perceived Stress Scale Questionnaire (PSS)

Anxiety Sensitivity Index (ASI)

\section{Sleep quality}

Polysomnography and actigraphy

Sleep quality/daytime sleepiness/sleep disorders

Pittsburgh Sleep Quality Index (PSQI)

Epworth Sleepiness Scale (ESS) 
Table 2 Schedule of physiological, cognitive, psychological, and neuroimaging assessments for the Brain in Motion // trial (Continued)

\begin{tabular}{llc}
\hline Assessment measure & $\begin{array}{c}\text { Screening } \\
\text { assessments }\end{array}$ & \multicolumn{2}{c}{ Visit (months) } \\
\cline { 2 - 4 } & $\mathbf{0}$ & $\mathbf{3}$ \\
\hline STOP-Bang & $\checkmark$ & $\checkmark$ \\
Insomnia Severity Index (ISI) & $\checkmark$ & $\mathbf{6}$ \\
Restless Legs Questionnaire & $\checkmark$ & $\checkmark$ \\
Health behaviour & & $\checkmark$ \\
Motivational Readiness Questionnaire & $\checkmark$ & $\checkmark$ \\
Exercise Benefits/Barriers Scale & $\checkmark$ & $\checkmark$ \\
EuroQoL Five-Dimension Quality of Life Scale (EQ-5D-5L) & $\checkmark$ & $\checkmark$ \\
Exercise Self-Efficacy Scale (EXSE) & $\checkmark$ & $\checkmark$ \\
Adherence Intent and Self-Regulatory Processes Scale & $\checkmark$ & $\checkmark$ \\
\hline
\end{tabular}

complete a fourth session each week on their own in addition to the three supervised sessions. Participants can continue with their normal daily activities, such as taking prescribed medications, and activity pattern. This information will be captured in questionnaires (administered at the beginning, during, and completion of the study), logbooks (to record any additional independent unsupervised exercise), and actigraphy (which is used to track physical activity and sleep). At the end of the exercise interventions, no instructions or stipulations will be provided for continuing to exercise, but those in the health behaviour group are provided with telephone support to help them achieve their individual physical activity and exercise goals.

\section{Aerobic exercise intervention}

Participants randomized to this condition will take part in a 6-month aerobic training programme held 3 days per week. Each exercise session will comprised a 5-min warm-up, 20-40 min of aerobic exercise (walking or jogging), and 5-min cool-down and stretching. Individualized exercise prescriptions will follow the current principles and guidelines established by the American College of Sports Medicine (ACSM) and the American Heart Association (AHA [40]). As participants progress through the 6-month intervention, the duration of exercise will increase from $20 \mathrm{~min}$ (month 1) to $30 \mathrm{~min}$ (months 2 and 3 ) and to 40 min (months 4 to 6), with proportional increases to the corresponding warm-up and cool-down periods. Exercise intensity will be based on an individual's heart rate reserve (HRR) calculated by subtracting the resting heart rate from the maximal heart rate achieved during the incremental treadmill test conducted at baseline. Prescribed intensity will build from 30 to $45 \%$ of HRR (months 1 to 3 ) to mitigate the risk of injury and will progress to $60-70 \%$ HRR (months 4 to 6$)$. Polar ${ }^{\circledast}$ heart rate monitors will be used to check compliance with target heart rate zones. Heart rate data will be exported for analysis after each exercise session.

\section{Stretching-toning intervention}

Participants randomized to this condition will meet on a similar schedule to that of the aerobic exercise intervention group, but the training sessions will focus on stretching and toning exercises. This programme consists of balance work, stretching, and core activation exercises and other basic movement patterns (e.g., static lunges, walking dips, and squats). Based on prior RCTs of similar interventions, we expect this control to be ineffective or minimally effective for some measures of executive function and memory compared to aerobic exercise [32]. We anticipate that stretching and toning exercises will provide a good comparison condition to aerobic exercise by maintaining participant's enthusiasm and motivation.

\section{Health behaviour support follow-up}

Building on well-supported theoretical foundations [54], participants randomized to these groups will undergo a 1-year of individually tailored telephone support to facilitate and maintain behaviour change [55]. Given that no "best" strategy exists for increasing physical activity levels [56], this behavioural support intervention will use an integrated model of modifiable determinants of physical activity behaviour to address intra- and interpersonal determinants [54, 57]. Support provided will address one or more constructs within the domains of cognitive, behavioural, and social support, with the specific behaviour change strategy determined by discussion with participants. Cognitive strategies target peoples' thoughts and perspectives surrounding exercise behaviour and include techniques such as inquiring about individuals' perceptions of the reasons underlying their motivation, intentions, and attitudes/beliefs. The behavioural domain will target strategies to alter exercise behaviour, focusing on developing skills to initiate or cue exercise behaviour and/or reduce counterproductive behaviours, including strategies such as goal setting, stimulus control, action planning, and coping planning. 
Finally, social strategies emphasize interpersonal resources and barriers and focus on seeking and leveraging interpersonal resources and social environments to encourage exercise, such as seeking group and/or partner exercise settings, emotional and/or informational social support, and modelling.

Participants allocated to receive support will be contacted by telephone to take part in a 15-30-min support discussion with a trained study staff member. Because early repetition of healthy behaviours is thought to precipitate larger increases in automaticity and habit formation [58], participants will receive four support phone calls within the first half of the behaviour support intervention and two in the second half.

\section{Primary outcome}

The primary outcome will be assessed at baseline and 6 and 18 months in the research lab by personnel blinded to which group the participant was randomized. Due to the length of the study, the outcomes measured at 6 and 18 months will likely be conducted by a different person who will be trained and validated on all study procedures they administer.

\section{Cognitive composite score}

The primary outcome of interest is an overall cognitive composite score measured after the completion of the exercise intervention (i.e., at 6 months). Participants allocated to the aerobic exercise intervention will be compared to those allocated to the stretching-toning exercise one. The cognitive composite score incorporates five cognitive domains and their respective tests listed as follows:

1. Executive function: verbal fluency, Trail Making Test - part B (TMT-B)

2. Visual perceptual skills: Line Orientation, and Card Rotations Test

3. Complex attention: Digit and Sustained Attention to Responding Task (SART)

4. Processing speed: Symbol-Digit Modalities Test (oral and written; SDMT-O/-W) and the Trail Making Test - part A (TMT-A)

5. Memory: Hopkins Verbal Learning Test (HVLT) and Brief Visuospatial Memory Test - Revised (BVMT-R)

Raw scores of each cognitive test will be transformed to a common metric based on standard scores ( $\mathrm{Z}$ scores). Z scores will be calculated by subtracting the normative mean (retrieved from prior studies or observations) from each participant's component test score [59]. This difference will then be divided by the standard deviation of the normative sample [59]. Z scores from each cognitive test will be summed (i.e., each domain will be equally weighted), averaged within each of the five domains to obtain a domain score, and then compared statistically across the two interventions (aerobic vs stretching-toning) [60]. Apart from considering the overall cognitive composite score, specific domains hypothesized to be most sensitive to the aerobic exercise intervention (e.g., executive functioning and processing speed) will be analysed as secondary outcomes.

\section{Secondary outcomes}

The secondary outcome will be assessed at baseline and 6 and 18 months in the research lab (except for sleep studies, which will be conducted at the participant's home) by personnel blinded to which group the participant was randomized. Due to the length of the study, outcomes measured at 6 and 18 months will likely be conducted by a different person who will be trained and validated on all study procedures they administer.

\section{Cognition}

Apart from considering the overall cognitive composite score, specific domains hypothesized to be most sensitive to the aerobic exercise intervention (e.g., executive functioning and processing speed) will be analysed as secondary outcomes. The specific neuropsychological tests were chosen based on their relevance to ADRD and the component domains known to be affected by aerobic fitness training (executive functioning, complex attention, processing speed, and verbal memory [34, 61-63]) (see Table 3 for a complete listing of the individual neuropsychological tests that will be administered).

\section{Cerebral blood flow}

A CBF test will be conducted to investigate whether aerobic exercise enhances brain health (e.g. increase resting $\mathrm{CBF}$ ) and, if yes, whether increased resting CBF due to training will be maintained over 1 year after the exercise intervention completion. Cerebrovascular responses to increases in arterial partial pressure of carbon dioxide $\left(\mathrm{CO}_{2}\right)$ and to submaximal exercise (measures of cerebrovascular reserve) will be assessed using transcranial Doppler ultrasound. The experimental set-up and protocol used are described in detail in a previous publication from our laboratory [52]. Outcome measures for these tests include baseline $\mathrm{CBF}$ and cerebrovascular reserve (i.e., brain responses to $\mathrm{CO}_{2}$ and exercise), heart rate, blood pressure, and blood rheology (i.e., haematocrit, viscosity, and aggregation).

\section{Maximal aerobic oxygen uptake}

A protocol to assess maximal oxygen uptake $\left(\dot{\mathrm{V}}_{2} \max \right)$ will be performed to test the hypothesis that aerobic exercise will enhance aerobic fitness as measured by 
Table 3 Neuropsychological tests administered for the Brain in Motion II trial

\begin{tabular}{|c|c|}
\hline Neuropsychological test by domain & Description (approximate time in min) \\
\hline \multicolumn{2}{|l|}{ Premorbid intellectual ability } \\
\hline The Spot-the-Word Test & $\begin{array}{l}\text { Silent lexical decision task; pairs of items comprising one word and one non-word are presented ( } 5 \\
\text { min) }\end{array}$ \\
\hline \multicolumn{2}{|l|}{ Cognitive screening } \\
\hline Montreal Cognitive Assessment (MoCA) & Brief cognitive screening tool, used to stratify and characterize the participants at baseline (10 min) \\
\hline \multicolumn{2}{|l|}{ Complex attention } \\
\hline Digit & $\begin{array}{l}\text { Sequence of number strings ( } 2-8 \text { digits in length) presented for recall in the same order or backwards } \\
\text { ( } 8 \text { min) }\end{array}$ \\
\hline $\begin{array}{l}\text { Sustained Attention to Responding Task } \\
\text { (SART) }\end{array}$ & $\begin{array}{l}\text { Computer-based task, withholding key presses to infrequent and unpredictable stimuli amid } 225 \\
\text { target stimuli (8 min) }\end{array}$ \\
\hline \multicolumn{2}{|l|}{ Processing speed } \\
\hline $\begin{array}{l}\text { Symbol-Digit Modalities Test (oral and } \\
\text { written; SDMT-O/-W) }\end{array}$ & Written and oral speeded task matching digits with geometric symbols according to a legend (5 min) \\
\hline Trail Making Test - part A (TMT-A) & $\begin{array}{l}\text { Timed test of visuo-motor sequencing and scanning; speed of performance linked to functional out- } \\
\text { comes (e.g., driving ability; } 3 \text { min) }\end{array}$ \\
\hline \multicolumn{2}{|l|}{ Language } \\
\hline Boston Naming Test - short version (BNT) & Naming vocabulary test; 15 pictures presented sequentially (5 min) \\
\hline Token Test for Receptive Language & $\begin{array}{l}\text { Identify and manipulate } 20 \text { tokens of varying size, shape, and colour in response to given directions } \\
\text { ( } 7 \mathrm{~min})\end{array}$ \\
\hline \multicolumn{2}{|l|}{ Verbal memory } \\
\hline Hopkins Verbal Learning Test (HVLT) & $\begin{array}{l}\text { Twelve-word list presented for } 5 \text { trials with immediate recall, cured recall, multiple choice recognition, } \\
\text { and delayed recall measured ( } 14 \mathrm{~min})\end{array}$ \\
\hline $\begin{array}{l}\text { Brief Visuospatial Memory Test - Revised } \\
\text { (BVMT-R) }\end{array}$ & Draw and recognize geometric figures that were presented 25 min earlier (10 min) \\
\hline \multicolumn{2}{|l|}{ Executive function } \\
\hline Verbal fluency & Generation of unique words beginning with designated letters (7 min) \\
\hline Trail Making Test - part B (TMT-B) & $\begin{array}{l}\text { Timed test of visuo-motor sequencing and scanning; performance speed linked to functional out- } \\
\text { comes ( } 3 \mathrm{~min})\end{array}$ \\
\hline Judgement of Line Orientation & $\begin{array}{l}\text { Matching the angle and orientation of } 2 \text { angled lines to a set of } 11 \text { lines arranged in a semi-circle (10 } \\
\text { min) }\end{array}$ \\
\hline Card Rotations Test & Identify which of six irregularly shaped and rotated cards are the same as a target card ( 4 min) \\
\hline
\end{tabular}

$\dot{\mathrm{V}} \mathrm{O}_{2} \max$ and that the $\dot{\mathrm{V}} \mathrm{O}_{2} \max$ improvement due to training will be maintained over 1 year after completion of the exercise intervention. The $\dot{\mathrm{VO}}_{2}$ max test will be conducted on a treadmill and will involve a ramp increase in workload aimed at reaching the subject's $\dot{\mathrm{V}}_{2}$ max within 8-12 min, according to ACSM recommendations [64]. Exercise testing will be completed in the Clinical and Translational Exercise Physiology Laboratory, Cumming School of Medicine, University of Calgary by certified exercise physiologists (Canadian Society of Exercise Physiology). The experimental set-up and the protocol used are similar to those described in previous studies from our lab (see [65]). Outcome measures for this test include $\dot{\mathrm{VO}}_{2}$ max, ventilatory thresholds, heart rate, and blood pressure.

\section{Blood biomarkers}

Blood markers will be analysed to examine if they moderate the observed effects of aerobic exercise on cognitive outcomes. We hypothesize aerobic exercise will promote more favourable changes in the blood biomarkers than stretching-toning exercise, and changes in blood biomarkers in the aerobic exercise group will be associated with cognition enhancement. Sex steroid hormone status (estradiol, progesterone, testosterone, and sex hormone-binding globulin), lipids (cholesterol, high- and low-density lipoprotein, and triglycerides), thyroid (thyroidstimulating hormone), renal (creatinine), hepatic (alanine aminotransferase and bilirubin), and cardiovascular disease markers (hsCRP) will be measured. Complete blood count will be quantified immediately after blood collection, while other markers will be assessed in batches after blood samples are centrifuged and frozen at $-80^{\circ} \mathrm{C}$. Details of the blood volumes required and assays to be used (including reliability, validity, and coefficients of variation) are included in Table 4. 
Table 4 Details of the blood volume required, assays to be used, intra-assay variability, and measuring range

\begin{tabular}{|c|c|c|c|c|c|}
\hline Markers & $\begin{array}{l}\text { Collection } \\
\text { tubes }\end{array}$ & Assay & $\begin{array}{l}\text { Sample } \\
\text { volume }\end{array}$ & $\begin{array}{l}\text { CV\% intra- } \\
\text { assay }\end{array}$ & $\begin{array}{l}\text { Measuring } \\
\text { range }\end{array}$ \\
\hline \multicolumn{6}{|l|}{ Hormones } \\
\hline Estradiol & PST/SST & Electrochemiluminescent immunoassay & $\begin{array}{l}500 \mu \mathrm{L} \\
\text { plasma/serum }\end{array}$ & 6 & $\begin{array}{l}8.4-15,781 \\
\mathrm{pmol} / \mathrm{L}\end{array}$ \\
\hline Progesterone & PST/SST & Chemiluminescent immunoassay & $200 \mu \mathrm{L}$ plasma & 6 & $\begin{array}{l}0.48-190.8 \\
\mathrm{nmol} / \mathrm{L}\end{array}$ \\
\hline Testosterone & PST/SST & Chemiluminescent immunoassay & $\begin{array}{l}0.5 \mathrm{~mL} \text { plasma/ } \\
\text { serum }\end{array}$ & 9 & $\begin{array}{l}0.35-52.1 \\
\mathrm{nmol} / \mathrm{L}\end{array}$ \\
\hline $\begin{array}{l}\text { Free } \\
\text { Testosterone }\end{array}$ & Calculated & & & & \\
\hline SHBG & SST & Chemiluminescent immunoassay & $0.5 \mathrm{~mL}$ serum & 7 & $\begin{array}{l}0.02-180 \\
\mathrm{nmol} / \mathrm{L}\end{array}$ \\
\hline Albumin & PST/SST & Bromcresol purple binding/colorimetric & $\begin{array}{l}0.2 \mathrm{~mL} \text { plasma/ } \\
\text { serum }\end{array}$ & 2.5 & $1-100 \mathrm{~g} / \mathrm{L}$ \\
\hline \multicolumn{6}{|l|}{ Lipids } \\
\hline $\begin{array}{l}\text { Cholesterol } \\
\text { (total) }\end{array}$ & PST/SST & Enzymatic colorimetric — cholesterol esterase and cholesterol oxidase & $\begin{array}{l}0.2 \mathrm{~mL} \text { plasma/ } \\
\text { serum }\end{array}$ & 1.7 & $\begin{array}{l}0.08-20.8 \\
\mathrm{mmol} / \mathrm{L}\end{array}$ \\
\hline LDL & Calculated & & & & \\
\hline $\mathrm{HDL}$ & PST/SST & $\begin{array}{l}\text { Enzymatic colorimetric-PEG-modified cholesterol esterase and } \\
\text { cholesterol oxidase }\end{array}$ & $\begin{array}{l}0.2 \mathrm{~mL} \text { plasma/ } \\
\text { serum }\end{array}$ & 2.5 & $\begin{array}{l}0.10-3.12 \\
\mathrm{mmol} / \mathrm{L}\end{array}$ \\
\hline TG & PST/SST & $\begin{array}{l}\text { Hydrolysis of TG by a lipoprotein lipase to glycerol, followed by } \\
\text { oxidation to form hydrogen peroxide }\end{array}$ & $\begin{array}{l}0.2 \mathrm{~mL} \text { plasma/ } \\
\text { serum }\end{array}$ & 2.5 & $\begin{array}{l}0.10-11.40 \\
\mathrm{mmol} / \mathrm{L}\end{array}$ \\
\hline \multicolumn{6}{|l|}{ Thyroid } \\
\hline $\mathrm{TSH}$ & PST/SST & Two-site chemiluminescent immunoassay (Siemens Centaur reagent) & $\begin{array}{l}1.0 \mathrm{~mL} \text { plasma/ } \\
\text { serum }\end{array}$ & 5.0 & $\begin{array}{l}0.01-150 \\
\mathrm{mU} / \mathrm{L}\end{array}$ \\
\hline \multicolumn{6}{|l|}{ Kidney } \\
\hline $\mathrm{CBC}$ & EDTA & Beckman-Coulter GEN-S (Calibrated with SCAL kit) & $\begin{array}{l}4 \mathrm{~mL} \text { whole } \\
\text { blood }\end{array}$ & & \\
\hline Creatinine & PST/SST & Enzymatic colorimetric_creatininase & $\begin{array}{l}0.2 \mathrm{~mL} \text { plasma/ } \\
\text { serum }\end{array}$ & 2.0 & $\begin{array}{l}5- \\
3000 \mu \mathrm{mol} / \mathrm{L}\end{array}$ \\
\hline \multicolumn{6}{|l|}{ Hepatic } \\
\hline ALT & PST/SST & Rate UV without pyridoxal phosphate activation & $\begin{array}{l}0.2 \mathrm{~mL} \text { plasma/ } \\
\text { serum }\end{array}$ & 3.0 & $4-600 \mathrm{U} / \mathrm{L}$ \\
\hline $\begin{array}{l}\text { Bilirubin } \\
\text { (total) }\end{array}$ & PST/SST & Colorimetric (diazonium ion, with blank) & $\begin{array}{l}0.2 \mathrm{~mL} \text { plasma/ } \\
\text { serum }\end{array}$ & 3.0 & $\begin{array}{l}2-600 \mu \mathrm{mol} / \\
\mathrm{L}\end{array}$ \\
\hline \multicolumn{6}{|l|}{ CVD marker } \\
\hline hsCRP & PST/SST & Particle enhanced turbidimetric assay & $\begin{array}{l}0.2 \mathrm{~mL} \text { plasma/ } \\
\text { serum }\end{array}$ & 2.0 & $0.1-20 \mathrm{mg} / \mathrm{L}$ \\
\hline
\end{tabular}

Notes: All analyses will be carried out at Calgary Laboratory Services. At baseline (0 month), 27-30 mL of blood will be required for measurements of hormones, lipids, and screening markers of thyroid, kidney, hepatic function, and hsCRP $(3 \times 5 \mathrm{~mL}$ gold (SST tubes) $+3 \times 4 \mathrm{~mL}$ lavender (EDTA tubes)). At the other time points ( 6 and 18 months), only $18-20 \mathrm{~mL}$ of blood will be required for measurements of hormones, lipid profiles, and hsCRP ( $2 \times 5 \mathrm{~mL}$ gold (SST tubes) $+2 \times 4 \mathrm{~mL}$ lavender (EDTA tubes))

Abbreviations: PST, plasma separator tube; SST, serum separator tube; EDTA, ethylenediaminetetra acetic acid in a tripotassium or disodium base; CV\%, coefficient of variation; $S H B G$, sex hormone binding globulin; $L D L$, low-density lipoprotein; $H D L$, high-density lipoprotein; $T G$, triglycerides; $T S H$, thyroid-stimulating hormone; $C B C$, complete blood count; $A L T$, alanine aminotransferase; $C V D$, cardiovascular disease; $h s C R P$, high-sensitivity $C$-reactive protein

\section{Genetic risk factors}

DNA samples will be collected at baseline to test the hypothesis that genetic risk factors moderate exerciserelated cognitive outcomes. We hypothesize aerobic exercise will promote greater cognitive enhancement in those with greater changes in neurotrophic factors (e.g., BDNF and IGF-1) compared to stretching-toning exercise. Genomic DNA will be obtained from buffy coat blood samples (Gentra Puregene Blood Kit; Qiagen, Venlo, Netherlands). DNA samples will be sent for polymerase chain reaction amplification and Sanger sequencing (BigDye v1.1 Cycle Sequencing Kit; Applied Biosystems, Foster City, CA) on ABI 3130XL Genetic Analyzer (Applied Biosystems). These techniques will be used to genotype selected genes that have shown to influence cognitive performance and that are associated 
with neuronal integrity. These genes include BDNF, APOE, IGF-1, catechol-O-methyl-transferase (COMT), angiotensin-converting enzyme (ACE), insulin-degrading enzyme (IDE), methylenetetrahydrofolate reductase (MTHFR), clusterin (CLU), complement component (3b/4b) receptor 1 (CR1), bridging integrator 1 (BIN1), phosphatidylinositol-binding clatherin assembly protein (PICALM), 3-hydroxy-3-methylglutaryl-CoA reductase (HMGCR), and translocase of outer mitochondrial membrane (TOMM40).

\section{Risk/protective factors}

Self-administered validated questionnaires will be used to quantify the role of additional lifestyle factors on cognitive functioning at baseline, and changes over the intervention and follow-up periods. Measures include changes in dietary intake, food frequency, supplement intake [66], physical activity [67, 68], motivation for physical activity [69], cognitive activities [62], mood changes $[70,71]$, social support [72-74], social engagement $[72,75]$, and modifiable ADRD risk/protective factors [76], including attention deficit hyperactivity disorder (ADHD) [77]. These data will provide collective insights on the possible mechanisms by which our interventions improve cognitive functioning and help to prevent ADRD [76].

\section{Brain structure and function}

Brain MRI will be used to test the hypotheses that 6 months of aerobic training, but not stretching-toning training, is associated with the following: (1) increases in brain volume, specifically cortical grey and white matter volume, including the frontal lobes and cortical areas implicated in attention control and memory processes [27] and hippocampal volume [78]; (2) increases in MRI measured resting CBF [79]; (3) reduced progression of white matter hyperintensities of presumed vascular origin; and (4) increases in functional connectivity of the default mode network [80].

Neuroimaging data will be collected on the 3-T scanner (General Electric Discovery 750, GE Healthcare, USA). Our 37-min MRI protocol is built on the multisite Alzheimer Disease Neuroimaging Initiative protocol [81]. Our protocol (see Table 5) includes a highresolution whole-brain 3D T1-weighted structural image, a T2-weighted fluid-attenuated inversion recovery (FLAIR) image to evaluate white matter hyperintensities, resting perfusion measured with arterial spin labelling (ASL), high angular resolution diffusion imaging to calculate mean diffusivity and fractional anisotropy and for tractography analysis, and resting-state blood oxygen level-dependent (BOLD) functional MRI for functional connectivity analyses. Further, we will generate cerebrovascular reactivity maps from BOLD and ASL time series acquired during hypercapnia [82-87]. It is expected that $60-70 \%$ of participants will consent to the MRI component of the study; however, participants with contraindication for an MRI exam will not be included in this part of the study. Therefore, an additional 10$20 \%$ non-completion rate is expected for participants who do consent to an MRI.

\section{Sleep quality}

We will test whether the beneficial effect of aerobic exercise on cognitive functioning is modulated by an improvement in sleep quality. We will use three complementary modalities to monitor sleep quality. First, we will apply the Pittsburgh Sleep Quality Index (PSQI) Questionnaire [88], which assesses the participants' quality of sleep during the previous month. Second, we will measure inactivity as a proxy for sleep using actigraphy [89]. Finally, we will analyse sleep

Table 5 MRI acquisition parameters

\begin{tabular}{|c|c|c|c|c|c|c|}
\hline Sequence & $\begin{array}{l}\text { Repetition } \\
\text { time (ms) }\end{array}$ & $\begin{array}{l}\text { Echo } \\
\text { time } \\
\text { (ms) }\end{array}$ & $\begin{array}{l}\text { Voxel } \\
\text { size } \\
(\mathrm{mm} 3)\end{array}$ & $\begin{array}{l}\text { Band- } \\
\text { width } \\
(\mathrm{kHz})\end{array}$ & Others & $\begin{array}{l}\text { Scan } \\
\text { duration } \\
\text { (min:s) }\end{array}$ \\
\hline $\begin{array}{l}\text { T1w (inversion-recovery prepared } \\
\text { fast spoiled gradient echo) }\end{array}$ & 6.7 & 2.9 & $\begin{array}{l}1.0 \times 1.0 \\
\times 1.0\end{array}$ & 31.25 & Inversion time $=650 \mathrm{~ms}, 2 \times$ acceleration & $5: 31$ \\
\hline T2-FLAIR & 10,000 & 140 & $\begin{array}{l}0.9 \times 0.9 \\
\times 3.0\end{array}$ & 31.25 & Inversion time $=2250 \mathrm{~ms}, 3$ segments & $5: 01$ \\
\hline $\begin{array}{l}\text { Diffusion (spin-echo echo planar } \\
\text { imaging) }\end{array}$ & 8000 & 65 & $\begin{array}{l}2.2 \times 2.2 \\
\times 2.2\end{array}$ & 250.00 & $\begin{array}{l}2 \times \text { acceleration, } 30 \text { directions } b \text {-value }=1000,3 \\
b \text {-value }=0 \text { images }\end{array}$ & $4: 32$ \\
\hline $\begin{array}{l}\text { BOLD (echo planar imaging): } \\
\text { resting state and CVR }\end{array}$ & 2286 & 30 & $\begin{array}{l}3.5 \times 3.5 \\
\times 3.5\end{array}$ & 83.33 & $\begin{array}{l}2 x \text { acceleration, 5:00 rest, 2:00 hypercapnia, 1:11 } \\
\text { rest }\end{array}$ & $8: 11$ \\
\hline $\begin{array}{l}\text { pCASL (fast spin echo stack-of- } \\
\text { spirals): resting perfusion }\end{array}$ & 4786 & 10.2 & $\begin{array}{l}3.6 \times 3.6 \\
\times 5.0\end{array}$ & 62.50 & $\begin{array}{l}\text { Label duration }=1500 \text { ms, post-label delay }= \\
2025 \text { ms, } 2 \text { averages }\end{array}$ & $3: 21$ \\
\hline $\begin{array}{l}\text { Dual echo pCASL: simultaneous } \\
\text { BOLD and perfusion CVR }\end{array}$ & 4000 & $12.7 / 28$ & $\begin{array}{l}3.75 \times \\
3.75 \times 3.8\end{array}$ & 250.00 & $\begin{array}{l}\text { Label duration }=1600 \text { ms, post-label delay }= \\
1000 \text { ms, 2:16 rest, 2:00 hypercapnia, 2:00 rest }\end{array}$ & $6: 16$ \\
\hline
\end{tabular}

Abbreviations: FLAIR, weighted fluid attenuated inversion recovery; BOLD, resting-state blood oxygen level dependent; $C V R$, cerebrovascular reactivity; $p C A S L$, pseudo-continuous arterial spin labelling 
quality through an in-home-based overnight level two polysomnography (Embletta MPR PG, Natus Medical Inc., Pleasanton, $\mathrm{CA}$ ) and an ST1 proxy unit.

\section{Cost-utility analysis}

To estimate the cost-utility of our aerobic exercise intervention, we will assess costs associated with the intervention itself (e.g., recreational facility membership, personal trainer time, equipment), physical activity engaged in during the maintenance phase, and healthcare resource utilization. Using provincial administrative databases, costs of pharmaceuticals, primary care physician visits, emergency room visits, and hospitalizations will be calculated. We will use the EuroQoL Five-Dimension Five-Level Quality of Life Scale (EQ-5D-5L [90-92];) to measure the quality of life. The scores will be translated into utilities using the Canadian social value set [93].

\section{Data management and monitoring}

This study will be conducted in a manner consistent with good clinical practice. Drs. MJP, MDH, and DBH will oversee all research activities. The study coordinator will be responsible, in part, for the communication with all investigators. The team leader, project manager, and site coordinator will hold weekly meetings; full team meetings will be held monthly.

The data will be collected in paper forms, recorded in secured and encrypted electronic report forms (REDCap) by trained personnel, and verified by an independent trained staff member. Once the data is verified, the documents will be scanned and uploaded to REDCap. The data storage will be in secure servers requiring twofactor authentications. All the paper forms (screening and demographic data and outcome measures) will be recorded by participant number and stored in locked filing cabinets, to which only the study coordinator and primary investigator possess a key, after verifications.

Investigators will maintain data and records on file for a minimum period of 25 years. These will include the enrolment records, receipts, undertakings signed by the qualified investigator in this study, copies of the proto$\mathrm{col}$, and attestation by the Research Ethics Board that our study carries out its functions in a manner consistent with good clinical practice.

Amendments in the research protocol, including consent form changes, will be communicated to investigators and local REB. Individuals already enrolled in the study will be asked to sign an updated version of the consent form if applicable.

This RCT does not require regulation by Health Canada (no Clinical Trial Application is sought). Serious adverse event (SAE) information will be collected for the duration of the participant's involvement in the RCT. SAEs will be managed according to the best current standard of care and reported to local REB according to good clinical practices. All SAEs will be reported within one business day, in a structured narrative explaining the events that occurred. An internal safety monitor will adjudicate all SAEs for report completeness, seriousness of event, and relationship to study interventions.

\section{Data withdrawal}

Participants may request the removal and permanent deletion of data and/or biological samples collected from their participation at any time in the study up until their withdrawal. Data collected up to the date of the withdrawal will be retained in the study to preserve its integrity. Participants who withdraw before completion of the exercise intervention study will be invited and encouraged to participate in all follow-up assessments unless there are safety concerns.

\section{Data storage and confidentiality}

Identifying information will be kept in locked cabinets in the study coordinator's office. As such, research assistants will only be provided with a unique number that has been given to each participant upon enrollment in the study. As we will be assessing various parameters that are dependent on age, we will need to retain the participants' date of birth in order to calculate their age at each assessment period. This is crucial to our data analysis, which will begin once data collection is complete.

Data storage will be in secure servers requiring twofactor authentication. Data are backed up at a remote site for safety in the event of a natural disaster. Participant files will also be stored in a locked cabinet in the study coordinator's office, to which only the study coordinator and primary investigator possess a key.

\section{Dissemination}

This RCT is registered with the publicly accessible www. clinicaltrials.gov registry for dissemination and data sharing purposes. RCT results will be published in a high-impact, peer-reviewed journal no more than 12 months after the end of the participant 18-month assessment visits and made freely available for public access within 6 months of publication. We expect to prepare up to ten publications addressing the different facets of this work. We will also present our results at national or international scientific conferences. We will disseminate our study findings on our website, in letters to the editor, participation in online journal clubs, through $\mathrm{Al}$ berta Health Services (AHS) newsletters, and internal publications at the University of Calgary and AHS. Similar routes will disseminate the results to other knowledge user team members and partners. Data and biological samples collected during this RCT will be 
made available to other qualified researchers with the informed consent of participants; data and samples will be de-identified to protect participant confidentiality and privacy.

\section{Statistical analyses}

The primary outcome analysis will use mixed-effects regression analysis to assess the effects of exercise on a composite cognitive score where the aerobic exercise intervention group will be compared to the stretchingtoning group while adjusting for the participants' baseline characteristics (age, sex, MoCA score, years of education, and baseline physical fitness level). The adjusted estimates of the mean change in cognitive composite score for each group will be reported along with the corresponding 95\% confidence intervals. Statistical significance will be set at $P<0.05$, and all tests will be twosided. The assessment of effect modification (heterogeneity of treatment effect) will be performed with the inclusion of multiplicative interaction terms for age, sex, APOE status, $\mathrm{CBF}, \dot{\mathrm{V}} \mathrm{O}_{2} \max$, and sleep quality. A final analysis plan, which includes analyses of the secondary outcomes and strategies for handling missing/incomplete data, will be formalized by the investigators prior to breaking the blind. The data analysis will only begin once data collection is complete.

\section{Discussion}

Results from this RCT will provide additional evidence on the cerebrovascular/physiological, genetic, neuroimaging, sleep, cognitive, and other psychological mechanisms by which 6 months of aerobic exercise may improve cognitive function-in comparison with a stretching-toning intervention-in older adults at elevated risk of ADRD. In addition, data from this study will help determine if any gains seen in cognitive functioning with aerobic exercise are maintained and potentially enhanced by a behavioural support intervention. Given that aerobic exercise is safe, economical, and can be implemented in community settings, our results will have substantial practical importance as they will provide novel evidence that can be used to inform exercise recommendations for the target population (i.e., older individuals at risk of ADRD).

Notable strengths of the current study include a relatively large sample size $(N=264)$, ample postintervention follow-up period (at 18 months), blinded (in the assessment of outcome measures) RCT design, collection of a multitude of physiological and psychological variables via "gold standard" techniques that may prove to mediate or moderate the relationship among exercise, cognition, and brain health. The ability to characterize how these intervening variables covary with improvements in fitness and cognition due to exercise will provide a wealth of information that may be clinically actionable for those at elevated risk of ADRD due to CVD risk factors. The Brain in Motion II Study will individualize aerobic exercise prescriptions based on the fitness levels of each individual (HRR) and track adherence to these training prescriptions via a continuous collection of HR data during exercise sessions. The ability to monitor and measure adherence beyond simple measures of session attendance yields important insights regarding optimal exercise intensity required for cerebrovascular and cognitive benefit from exercise.

While an inactive control group could be considered appropriate from an interval validity standpoint, the decision to compare the aerobic exercise intervention to a stretching-toning one was based on consideration of the limitations associated with the use of an inactive control arm. As most people are aware of the benefits of the exercise, the use of an inactive control group could lead to issues with external validity and may also be considered ethically doubtful for several reasons further discussed in Hecksteden et al. [94]. Additionally, the stretchingtoning intervention has been shown to be ineffective or minimally effective compared to aerobic exercise, for several of our outcomes, including some measures of executive function and memory [32], $\dot{\mathrm{VO}}_{2} \max$ [95], BMI [96], and measures of cortical thickness in the frontal cortex [96].

Despite these strengths, this RCT has two main limitations. The nature of the interventions, aerobic exercise and stretching-toning, precludes a double-blind trial design. It is possible that the cognitive outcomes may be, at least partly, influenced by confounding factors, such as socialization offered by the exercise class, participants' differential expectations for improvement from one type of exercise, and systematic differences in their motivation to improve in fitness. Although these potential confounding variables are difficult to control in a RCT, a previous study showed that participants' expectations are very unlikely to drive cognitive improvements due to aerobic exercise training [97]. In this study, Stothart et al. (2014) conducted a large survey to examine if people would expect greater improvements in cognitive functioning after aerobic exercise training compared to a control condition (non-aerobic exercise training). Participants who completed the survey expected similar cognitive performance outcomes after aerobic and nonaerobic exercise interventions [97]. It also remains possible that 6 months of aerobic exercise might not be sufficient in length to positively impact cognitive functioning and/or that 1 year of behavioural support is insufficient in length to observe sustained improvements. The results will need to be compared to intermediate findings of those RCTs with longer exercise intervention and/or follow-up periods [35]. Evidence 
generated by this RCT would be used to inform conversations with primary and community care stakeholders regarding adaptation or incorporation of behavioural support modelled on what we did into the current and future care programmes.

These limitations notwithstanding the Brain in Motion II Study seeks to gain critical insights into the mechanisms by which exercise training improves cognition in older adults at elevated risk of ADRD and stands uniquely situated to do so by examining a large selection of salient physiological and psychological variables. The importance of answers to these questions cannot be overstated given the devastating magnitude of impact that ADRD currently have in the global ageing population.

\section{Trial status}

This trial is ongoing. Enrollment began in January 2017 and is expected to be completed in January 2025. This study reflects the first version of the protocol registered on ClinicalTrials.gov on January 30, 2017 (NCT03035851, https://clinicaltrials.gov/ct2/show/ NCT03035851). In response to the COVID-19 pandemic, the research team has adopted extensive additional safety procedures in accordance with the national and provincial public health guidelines, which include an approved Workspace Safety Plan and an ethics modification. Participants enrolled at the time of the public health emergency were given remote support to complete the full duration of the exercise programme. Post-exercise assessments (i.e., 6 months) were completed in the study laboratory on participants who were comfortable with the safety procedures in place after being informed of the steps taken and were willing to come in. At the time of this protocol study submission, enrolment of new participants is still on hold.

\footnotetext{
Abbreviations

ACSM: American College of Sports Medicine; ACE: Angiotensin-converting enzyme; ADRD: Alzheimer's disease and related dementias; AHA: American Heart Association; AHS: Alberta Health Services; ANCOVA: Analysis of covariance; APOE: Apolipoprotein E; ASL: Arterial spin labelling; BDNF: Brainderived neurotrophic factor; BIM II: Brain in Motion II; BIN1: Bridging integrator 1; BISQ: Brain Injury Screening Questionnaire; BMI: Body mass index; BOLD: Blood oxygen level-dependent; CBF: Cerebral blood flow; CLU: Clusterin; $\mathrm{CO}_{2}$ : Carbon dioxide; COMT: Catechol-O-methyl-transferase; CR1: Complement component (3b/4b) receptor 1; CVD: Cardiovascular disease; EQ-5D-5L: EuroQoL Five-Dimension Five-Level Quality of Life Scale; FLAIR: Fluid-attenuated inversion recovery; IDE: Insulin-degrading enzyme; IGF-1: Insulin-like growth factor; HMGCR: 3-Hydroxy-3-methylglutaryl-CoA reductase; HR: Heart rate; HRR: Heart rate reserve; MAC-Q: Memory Assessment Clinic Questionnaire; MoCA: Montreal Cognitive Assessment; MRI: Magnetic resonance imaging; MTHFR: Methylenetetrahydrofolate reductase; TICS-M: Modified Telephone Interview for Cognitive Status; TOMM40: Translocase of outer mitochondrial membrane; PAR-Q+: Physical Activity Readiness Questionnaire; PICALM: Phosphatidylinositol-binding clatherin assembly protein; PROBE: Prospective, Randomized, Open with Blinded End-Points; PSQI: Pittsburgh Sleep Quality Index; REB: Research Ethics Board; RCT: Randomized controlled trial; SAEs: Serious adverse events; $\dot{\mathrm{V}} \mathrm{O}_{2}$ max: Maximal oxygen uptake
}

\section{Acknowledgements}

We acknowledge the support from all the staff members and research assistants from the Brain in Motion I/ team and the Clinical and Translational Exercise Physiology Laboratory (Cumming School of Medicine, University of Calgary).

\section{Data monitoring committee}

There is no data monitoring committee; however, MJP, MDH, and DBH will oversee all research activities.

\section{Authors' contributions}

Conception and design: MJP, TJA, FC, PJH, HMH, MDH, DBH, JH, SL, MM, BP, $J M R$, and TS. Drafting of the manuscript: RLK, CMC, AMD, and MJP. Critical revision: RLK, CMC, AMD, MJP, TJA, FC, PJH, HMH, MDH, DBH, JH, SL, MM, BP, JMR, and TS. All authors read and approved the final manuscript.

\section{Funding}

This study is funded by the Canadian Institutes of Health Research (CIHR) and The Brenda Strafford Foundation Chair in Alzheimer Research (BSFCAR) RLK is supported by an NSERC BRAIN CREATE Postdoctoral Fellowship, The Brenda Strafford Foundation, and MITACS Elevate Award. CMC was funded by T. Chen Fong Post-Doctoral Fellowship in Medical Imaging Science. The funding bodies did not play any role in the design of the study; collection, analysis, and interpretation of the data; and writing of the manuscript.

\section{Availability of data and materials}

The final trial dataset will be available from the corresponding author on reasonable request.

\section{Declarations}

\section{Ethics approval and consent to participate}

The study protocol has been approved by the University of Calgary Conjoint Health Research Ethics Board (REB16-1199) and registered with ClinicalTrials.gov (NCT03035851). We will obtain written informed consent from all the participants before enrollment.

\section{Consent for publication}

Not applicable.

\section{Competing interests}

The authors declare that they have no competing interests.

\section{Author details}

${ }^{1}$ Department of Physiology \& Pharmacology, Cumming School of Medicine, University of Calgary, Calgary, Alberta T2N 4N1, Canada. ${ }^{2}$ Hotchkiss Brain Institute, Cumming School of Medicine, University of Calgary, Calgary, Alberta T2N 4N1, Canada. ${ }^{3}$ Department of Physiology \& Pharmacology, Cumming School of Medicine, University of Calgary, Calgary, Alberta, T2N 4N1, Canada, Calgary, Alberta, Canada. ${ }^{4}$ Department of Cardiac Sciences at the University of Calgary, Calgary, Alberta T2N 4N1, Canada. ${ }^{5}$ Libin Cardiovascular Institute of Alberta, Cumming School of Medicine, University of Calgary, Calgary, Alberta T2N 4N1, Canada. ${ }^{6}$ Department of Community Health Sciences at the University of Calgary, Calgary, Alberta T2N 4N1, Canada. ${ }^{7} \mathrm{O}$ 'Brien Institute for Public Health, Cumming School of Medicine, University of Calgary, Calgary, Alberta T2N 4N1, Canada. ${ }^{8}$ Sleep Centre, Foothills Medical Centre, University of Calgary, Calgary, Alberta T2N 4N1, Canada. ${ }^{9}$ Seniors Health Strategic Clinical Network ${ }^{\mathrm{T}}$, Alberta Health Services, Edmonton, Alberta, Canada.

${ }^{10}$ Department of Clinical Neurosciences at the University of Calgary, Calgary, Alberta T2N 4N1, Canada. ${ }^{11}$ Department of Medicine at the University of Calgary, T2N 4 N1, Calgary, Alberta, Canada. ${ }^{12}$ Department of Radiology at the University of Calgary, Calgary, Alberta T2N 4N1, Canada. ${ }^{13}$ Faculty of Kinesiology, University of Calgary, Calgary, Alberta T2N 4N1, Canada. ${ }^{14}$ CAIP Chair in Healthy Brain Aging, Calgary, Canada. ${ }^{15}$ Department of Family Medicine at the University of Calgary, Calgary, Alberta T2N 4N1, Canada. ${ }^{16}$ Brenda Strafford Foundation Chair in Alzheimer Research, Calgary, Alberta, Canada. ${ }^{17}$ Heritage Medical Research Building, Room 210, 3330 Hospital Drive NW, Calgary, Alberta T2N 4N1, Canada. 
Received: 9 September 2020 Accepted: 21 May 2021 Published online: 14 June 2021

\section{References}

1. Kontis V, Bennett JE, Mathers CD, Li G, Foreman K, Ezzati M. Future life expectancy in 35 industrialised countries: projections with a Bayesian model ensemble. Lancet. 2017;389(10076):1323-35. https://doi.org/10.1016/S01406736(16)32381-9.

2. WHO. No title [Internet]. 2021. Available from: https://www.who.int/initia tives/decade-of-healthy-ageing. Accessed on Feb 27, 2021.

3. Bushnik T, Tjepkema M, Martel L. Health-adjusted life expectancy in Canada. Health Reports. 2018;29:14-22.

4. WHO. WHO | 10 facts on dementia: Who; 2018

5. Alzheimer's Society of Canada. 2017-2018 Impact report. [Internet]. 2019 [cited 2019 Dec 5]. Available from: https://impactreport.alzheimer.ca/2018/ ?_ga=2.163251836.1943227130.1575580416-846924376.1567449910

6. Snowden M, Steinman L, Mochan K, Grodstein F, Prohaska TR, Thurman DJ, et al. Effect of exercise on cognitive performance in community-dwelling older adults: review of intervention trials and recommendations for public health practice and research. J Am Geriatr Soc. 2011;59(4):704-16. https:// doi.org/10.1111/j.1532-5415.2011.03323.x.

7. Imtiaz B, Tolppanen AM, Kivipelto M, Soininen $\mathrm{H}$. Future directions in Alzheimer's disease from risk factors to prevention. Biochem Pharmacol. 2014;88(4):661-70. https://doi.org/10.1016/j.bcp.2014.01.003.

8. de Asteasu MLS, Martínez-Velilla N, Zambom-Ferraresi F, Casas-Herrero Á, Izquierdo M. Role of physical exercise on cognitive function in healthy older adults: a systematic review of randomized clinical trials. Ageing Res Rev. 2017:37:117-34. https://doi.org/10.1016/j.arr.2017.05.007.

9. Karssemeijer EGA, Bossers WJR, Aaronson JA, Sanders LMJ, Kessels RPC, Olde Rikkert MGM. Exergaming as a physical exercise strategy reduces frailty in people with dementia: a randomized controlled trial. J Am Med Dir Assoc. 2019;20(12):1502-8 e1.

10. Buchman AS, Yu L, Wilson RS, Lim A, Dawe RJ, Gaiteri C, et al. Physical activity, common brain pathologies, and cognition in community-dwelling older adults. Neurology. 2019;92(8):e811-22. https://doi.org/10.1212/WNL. 0000000000006954.

11. Tari AR, Nauman J, Zisko N, Skjellegrind HK, Bosnes I, Bergh S, et al. Temporal changes in cardiorespiratory fitness and risk of dementia incidence and mortality: a population-based prospective cohort study. Lancet Public Heal. 2019;4(11):e565-74. https://doi.org/10.1016/\$2468-2667(1 9)30183-5.

12. Young J, Angevaren M, Rusted J, Tabet N. Aerobic exercise to improve cognitive function in older people without known cognitive impairment. Cochrane Database Syst Rev. 2015:4:CD005381

13. Barnes JN, Corkery AT. Exercise improves vascular function, but does this translate to the brain? Brain Plast. 2018;4(1):65-79. https://doi.org/10.3233/ BPL-180075.

14. Mattsson N, Tosun D, Insel PS, Simonson A, Jack CR, Beckett LA, et al. Association of brain amyloid- $\beta$ with cerebral perfusion and structure in Alzheimer's disease and mild cognitive impairment. Brain. 2014;137(Pt 5): 1550-61. https://doi.org/10.1093/brain/awu043.

15. Katz PP, Pate R. Exercise as medicine. Ann Intern Med. 2016;165(12):880-1. https://doi.org/10.7326/M16-2086.

16. Tarumi T, Zhang R. Cerebral blood flow in normal aging adults: cardiovascular determinants, clinical implications, and aerobic fitness. $J$ Neurochem. 2018;144(5):595-608. https://doi.org/10.1111/jnc.14234.

17. Chen Z, Zhong C. Decoding Alzheimer's disease from perturbed cerebral glucose metabolism: implications for diagnostic and therapeutic strategies. Prog Neurobiol. 2013;108:21-43. https://doi.org/10.1016/j.pneurobio.2013.06. 004.

18. Larson EB, Wang L, Bowen JD, McCormick WC, Teri L, Crane P, et al. Exercise is associated with reduced risk for incident dementia among persons 65 years of age and older. Ann Intern Med. 2006;144(2):73-81. https://doi.org/1 0.7326/0003-4819-144-2-200601170-00004

19. Lin S, Yang $Y$, Qi Q, Wei $L$, Jing $N$, Jie $Z$, et al. The beneficial effect of physical exercise on cognitive function in a non-dementia aging Chinese population. Front Aging Neurosci. 2019;11:238. https://doi.org/10.3389/fna gi.2019.00238

20. Chen FT, Chen YP, Schneider S, Kao SC, Huang CM, Chang YK. Effects of exercise modes on neural processing of working memory in late middle- aged adults: an fMRI study. Front Aging Neurosci. 2019;11:224. https://doi. org/10.3389/fnagi.2019.00224.

21. Kramer AF, Colcombe S. Fitness effects on the cognitive function of older adults: a meta-analytic study—revisited. Perspect Psychol Sci. 2018;13(2): 213-7. https://doi.org/10.1177/1745691617707316.

22. Sofi F, Valecchi D, Bacci D, Abbate R, Gensini GF, Casini A, et al. Physical activity and risk of cognitive decline: a meta-analysis of prospective studies. J Intern Med [Internet]. 2011;269(1):107-17. https://doi.org/10.1111/j.1365-2 796.2010.02281.x.

23. Guiney $H$, Machado $L$. Benefits of regular aerobic exercise for executive functioning in healthy populations. Psychon Bull Rev. 2013;20(1):73-86. https://doi.org/10.3758/s13423-012-0345-4.

24. Middleton LE, Barnes DE, Lui LY, Yaffe K. Physical activity over the life course and its association with cognitive performance and impairment in old age. J Am Geriatr Soc. 2010;58(7):1322-6. https://doi.org/10.1111/j.1532-5415.201 0.02903.x.

25. Falck RS, Best JR, Davis JC, Liu-Ambrose T. The independent associations of physical activity and sleep with cognitive function in older adults. J Alzheimer's Dis. 2018;63(4):1469-84. https://doi.org/10.3233/JAD-170936.

26. Colcombe SJ, Erickson Kl, Raz N, Webb AG, Cohen NJ, McAuley E, et al. Aerobic fitness reduces brain tissue loss in aging humans. J Gerontol Ser A Biol Sci Med Sci. 2003;58:176-80

27. Colcombe SJ, Erickson KI, Scalf PE, Kim JS, Prakash R, McAuley E, et al. Aerobic exercise training increases brain volume in aging humans. $J$ Gerontol - Ser A Biol Sci Med Sci. 2006;61(11):1166-70. https://doi.org/10.1 093/gerona/61.11.1166

28. Erickson Kl, Prakash RS, Voss MW, Chaddock L, Hu L, Morris KS, et al. Aerobic fitness is associated with hippocampal volume in elderly humans. Hippocampus. 2009;19(10):1030-9. https://doi.org/10.1002/hipo.20547.

29. Johnson NF, Kim C, Clasey JL, Bailey A, Gold BT. Cardiorespiratory fitness is positively correlated with cerebral white matter integrity in healthy seniors. Neuroimage. 2012;59(2):1514-23. https://doi.org/10.1016/j.neuroimage.2011.08.032.

30. Sexton CE, Betts JF, Demnitz N, Dawes H, Ebmeier KP, Johansen-Berg H. A systematic review of MRI studies examining the relationship between physical fitness and activity and the white matter of the ageing brain. Neuroimage. 2016;131:81-90. https://doi.org/10.1016/j.neuroimage.2015.09.071.

31. Cotman CW, Berchtold NC. Exercise: a behavioral intervention to enhance brain health and plasticity. Trends Neurosci. 2002;25(6):295-301. https://doi. org/10.1016/S0166-2236(02)02143-4.

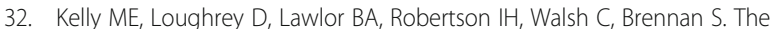
impact of exercise on the cognitive functioning of healthy older adults: a systematic review and meta-analysis. Ageing Res Rev. 2014;16:12-31. https:// doi.org/10.1016/j.arr.2014.05.002.

33. Gorelick PB, Furie KL, ladecola C, Smith EE, Waddy SP, Lloyd-Jones DM, et al. Defining optimal brain health in adults: a presidential advisory from the American Heart Association/American Stroke Association Stroke. Stroke. 2017:48(10):e284-303.

34. Colcombe S, Kramer AF. Fitness effects on the cognitive function of older adults: a meta-analytic study. Psychol Sci. 2003;13(2):213-7.

35. Sink KM, Espeland MA, Castro CM, Church T, Cohen R, Dodson JA, et al. Effect of a 24-month physical activity intervention vs health education on cognitive outcomes in sedentary older adults: the LIFE randomized trial. JAMA. 2015;314(8):781-90. https://doi.org/10.1001/jama.2015.9617.

36. Stefanidis KB, Askew CD, Greaves K, Summers MJ. The effect of non-stroke cardiovascular disease states on risk for cognitive decline and dementia: a systematic and meta-analytic review. Neuropsychol Rev. 2018;28(1):1-15. https://doi.org/10.1007/s11065-017-9359-z.

37. Lim ASP, Yu L, Kowgier M, Schneider JA, Buchman AS, Bennett DA. Sleep modifies the relation of APOE to the risk of Alzheimer disease and neurofibrillary tangle pathology. JAMA Neurol. 2013;70(12):1544-51. https:// doi.org/10.1001/jamaneurol.2013.4215.

38. Hansson L, Hedner T, Dahlöf B. Prospective randomized open blinded endpoint (PROBE) study. A novel design for intervention trials. Blood Press. 1992;1(2):113-9. https://doi.org/10.3109/08037059209077502.

39. Friedenreich CM, Courneya KS, Neilson HK, Matthews CE, Willis G, Irwin M, et al. Reliability and validity of the past year total physical activity questionnaire. Am J Epidemiol. 2006;163(10):959-70. https://doi.org/10.1093/aje/kwj112.

40. Nelson ME, Rejeski WJ, Blair SN, Duncan PW, Judge JO, King AC, et al. Physical activity and public health in older adults: recommendation from the American College of Sports Medicine and the American Heart Association. Circulation. 2007;39:1423-34. 
41. Lautenschlager NT, Cox KL, Flicker L, Foster JK, Van Bockxmeer FM, Xiao J, et al. Effect of physical activity on cognitive function in older adults at risk for Alzheimer disease: a randomized trial. JAMA. 2008;300(9):1027-37. https://doi.org/10.1001/jama.300.9.1027.

42. Bauman AE, Reis RS, Sallis JF, Wells JC, Loos RJF, Martin BW, et al. Correlates of physical activity: why are some people physically active and others not? Lancet. 2012;380(9838):258-71. https://doi.org/10.1016/S0140-6736(12)60735-1.

43. O'Bryant SE, Lacritz LH, Hall J, Waring SC, Chan W, Khodr ZG, et al. Validation of the new interpretive guidelines for the clinical dementia rating scale sum of boxes score in the National Alzheimer's Coordinating Center database. Arch Neurol. 2010;67(6):746-9.

44. De Jager CA, Budge MM, Clarke R. Utility of TICS-M for the assessment of cognitive function in older adults. Int J Geriatr Psychiatry. 2003;18(4):318-24. https://doi.org/10.1002/gps.830.

45. Go RCP, Duke LW, Harrell LE, Cody H, Bassett SS, Folstein MF, et al. Development and validation of a structured telephone interview for dementia assessment (STIDA): the NIMH Genetics Initiative. J Geriatr Psychiatry Neurol. 1997;10(4):161-7. https://doi.org/10.1177/089198879701 000407.

46. Dams-O'Connor K, Cantor JB, Brown M, Dijkers MP, Spielman LA, Gordon WA. Screening for traumatic brain injury: findings and public health implications. J Head Trauma Rehabil. 2014;29(6):479-89. https://doi.org/10.1 097/HTR.0000000000000099.

47. Nasreddine ZS, Phillips NA, Bédirian V, Charbonneau S, Whitehead V, Collin I, et al. The Montreal Cognitive Assessment, MoCA: a brief screening tool for mild cognitive impairment. J Am Geriatr Soc. 2005;53(4):695-9. https://doi. org/10.1111/j.1532-5415.2005.53221.x.

48. Crook TH, Feher EP, Larrabee GJ. Assessment of memory complaint in ageassociated memory impairment: the MAC-Q. Int Psychogeriatrics. 1992;4(2): 165-76. https://doi.org/10.1017/\$1041610292000991.

49. Jamnik VK, Warburton DER, Makarski J, McKenzie DC, Shephard RJ, Stone JA, et al. Enhancing the effectiveness of clearance for physical activity participation: background and overall process. Appl Physiol Nutr Metab. 2011;36(1):3-13.

50. Warburton DER, Gledhill N, Jamnik VK, Bredin SSD, McKenzie DC, Stone J, et al. Evidence-based risk assessment and recommendations for physical activity clearance: an introduction. Appl Physiol Nutr Metab. 2011;36:266-98.

51. Buckley R, Saling MM, Ames D, Rowe CC, Lautenschlager NT, MacAulay SL, et al. Factors affecting subjective memory complaints in the AIBL aging study: biomarkers, memory, affect, and age. Int Psychogeriatrics. 2013;25(8): 1307-15. https://doi.org/10.1017/S1041610213000665.

52. Tyndall AV, Davenport MH, Wilson BJ, Burek GM, Arsenault-Lapierre G, Haley $E$, et al. The brain-in-motion study: effect of a 6-month aerobic exercise intervention on cerebrovascular regulation and cognitive function in older adults. BMC Geriatr. 2013;13(1):21. https://doi.org/10.1186/1471-2318-13-21.

53. Lu K, Luo X, Chen PY. Sample size estimation for repeated measures analysis in randomized clinical trials with missing data. Int J Biostat. 2008;4(1):Article 9.

54. Hagger MS, Chatzisarantis NLD. An integrated behavior change model for physical activity. Exerc Sport Sci Rev. 2014;42(2):62-9. https://doi.org/10.124 9/JES.0000000000000008.

55. Kahn EB, Ramsey LT, Brownson RC, Heath GW, Howze EH, Powell KE, et al. The effectiveness of interventions to increase physical activity: a systematic review. Am J Prev Med. 2002;22(4 Suppl):73-107. https://doi.org/10.1016/ S0749-3797(02)00434-8.

56. Allen K, Morey MC. Improving patient treatment adherence. In: Physical activity and Adherence. New York: Springer; 2010. p. 9-38.

57. Michie S, Ashford S, Sniehotta FF, Dombrowski SU, Bishop A, French DP. A refined taxonomy of behaviour change techniques to help people change their physical activity and healthy eating behaviours: the CALO-RE taxonomy. Psychol Heal. 2011;26(11):1479-98. https://doi.org/10.1080/ 08870446.2010 .540664

58. Lally P, Van Jaarsveld CHM, Potts HWW, Wardle J. How are habits formed: modelling habit formation in the real world. Eur J Soc Psychol. 2010;40(6): 998-1009. https://doi.org/10.1002/ejsp.674.

59. Stud HR. Constructing composites to optimise cognitive outcomes. J Clin Stud [Internet]. 2017;9:40-5.

60. Brown AD, McMorris CA, Longman RS, Leigh R, Hill MD, Friedenreich CM, et al. Effects of cardiorespiratory fitness and cerebral blood flow on cognitive outcomes in older women. Neurobiol Aging. 2010;31(12):2047-57. https://doi.org/10.1016/j.neurobiolaging.2008.11.002.
61. Churchill JD, Galvez R, Colcombe S, Swain RA, Kramer AF, Greenough WT. Exercise, experience and the aging brain. Neurobiol Aging. 2002;23(5):94155. https://doi.org/10.1016/S0197-4580(02)00028-3.

62. Eskes GA, Longman S, Brown AD, McMorris CA, Langdon KD, Hogan DB, et al. Contribution of physical fitness, cerebrovascular reserve and cognitive stimulation to cognitive function in post-menopausal women. Front Aging Neurosci. 2010;2:137.

63. Smith PJ, Blumenthal JA, Hoffman BM, Cooper H, Strauman TA, WelshBohmer K, et al. Aerobic exercise and neurocognitive performance: a metaanalytic review of randomized controlled trials. Psychosom Med. 2010;72(3): 239-52. https://doi.org/10.1097/PSY.0b013e3181d14633.

64. ACSM's guidelines for exercise testing and prescription 9th Ed. 2014. J Can Chiropr Assoc. 2014;58(3):328.

65. Clark CM, Guadagni V, Mazerolle EL, Hill M, Hogan DB, Pike GB, et al. Effect of aerobic exercise on white matter microstructure in the aging brain. Behav Brain Res. 2019;373:112042. https://doi.org/10.1016/j.bbr.2019.112042.

66. Shatenstein B, Payette $\mathrm{H}$. Evaluation of the relative validity of the short diet questionnaire for assessing usual consumption frequencies of selected nutrients and foods. Nutrients. 2015;7(8):6362-74. https://doi.org/10.3390/ nu7085282.

67. Armstrong T, Bull F. Development of the World Health Organization Global Physical Activity Questionnaire (GPAQ). J Public Health (Bangkok). 2006;14(2): 66-70. https://doi.org/10.1007/s10389-006-0024-x.

68. Bull FC, Maslin TS, Armstrong T. Global physical activity questionnaire (GPAQ): nine country reliability and validity study. J Phys Act Heal. 2009;6(6): 790-804. https://doi.org/10.1123/jpah.6.6.790.

69. Markland D, Tobin V. A modification to the behavioural regulation in exercise questionnaire to include an assessment of amotivation. J Sport Exerc Psychol. 2004;26(2):191-6. https://doi.org/10.1123/jsep.26.2.191.

70. Zigmond AS, Snaith RP. The Hospital Anxiety and Depression Scale. Acta Psychiatr Scand. 1983;67(6):361-70. https://doi.org/10.1111/j.1600-0447.1983. tb09716.x

71. Yesavage JA, Brink TL, Rose TL, Lum O, Huang V, Adey M, et al. Development and validation of a geriatric depression screening scale: a preliminary report. J Psychiatr Res. 1982;17(1):37-49. https://doi.org/10.1016/ 0022-3956(82)90033-4.

72. Lubben J, Blozik E, Gillmann G, lliffe S, Von Kruse WR, Beck JC, et al. Performance of an abbreviated version of the Lubben Social Network Scale among three European community-dwelling older adult populations. Gerontologist. 2006;46(4):503-13. https://doi.org/10.1093/geront/46.4.503.

73. Sallis JF, Grossman RM, Pinski RB, Patterson TL, Nader PR. The development of scales to measure social support for diet and exercise behaviors. Prev Med (Baltim). 1987;16(6):825-36. https://doi.org/10.1016/0091-743 5(87)90022-3.

74. Martire LM, Stephens MAP, Mogle J, Schulz R, Brach J, Keefe FJ. Daily spousal influence on physical activity in knee osteoarthritis. Ann Behav Med. 2013;45(2):213-23. https://doi.org/10.1007/s12160-012-9442-x.

75. Kremen WS, Lachman ME, Pruessner JC, Sliwinski M, Wilson RS. Mechanisms of age-related cognitive change and targets for intervention: social interactions and stress. J Gerontol - Ser A Biol Sci Med Sci. 2012;67(7):760-5. https://doi.org/10.1093/gerona/gls125.

76. Anstey KJ, Cherbuin N, Herath PM. Development of a new method for assessing global risk of Alzheimer's disease for use in population health approaches to prevention. Prev Sci. 2013;14(4):411-21. https://doi.org/10.1 007/s11121-012-0313-2.

77. Kessler RC, Adler L, Ames M, Demler O, Faraone S, Hiripi E, et al. The World Health Organization Adult ADHD Self-Report scale (ASRS): a short screening scale for use in the general population. Psychol Med. 2005;35(2):245-56. https://doi.org/10.1017/S0033291704002892.

78. Erickson KI, Voss MW, Prakash RS, Basak C, Szabo A, Chaddock L, et al. Exercise training increases size of hippocampus and improves memory. Proc Natl Acad Sci U S A. 2011;108(7):3017-22. https://doi.org/10.1073/pnas.1015950108.

79. Burdette $\mathrm{JH}$, Laurienti PJ, Espeland MA, Morgan A, Telesford Q, Vechlekar $C D$, et al. Using network science to evaluate exercise-associated brain changes in older adults. Front Aging Neurosci. 2010;2:23.

80. Voss MW, Prakash RS, Erickson Kl, Basak C, Chaddock L, Kim JS, et al. Plasticity of brain networks in a randomized intervention trial of exercise training in older adults. Front Aging Neurosci. 2010;2:32.

81. Jack CR, Bernstein MA, Fox NC, Thompson P, Alexander G, Harvey D, et al. The Alzheimer's Disease Neuroimaging Initiative (ADNI): MRI methods. J J Magn Reson Imaging. 2008;27(4):685-91. https://doi.org/10.1002/jmri.21049. 
82. Hoge RD, Atkinson J, Gill B, Crelier GR, Marrett S, Pike GB. Linear coupling between cerebral blood flow and oxygen consumption in activated human cortex. Proc Natl Acad Sci U S A. 1999;96(16):9403-8. https://doi.org/10.1 073/pnas.96.16.9403.

83. Hoge RD, Atkinson J, Gill B, Crelier GR, Marrett S, Pike GB. Investigation of BOLD signal dependence on cerebral blood flow and oxygen consumption: the deoxyhemoglobin dilution model. Magn Reson Med. 1999;42(5):849-63. https://doi.org/10.1002/(SICI)1522-2594(199911)42:5<849::AID-MRM4>3.0. $\mathrm{CO} ; 2-\mathrm{Z}$.

84. Hamer M, Kivimaki M, Steptoe A. Longitudinal patterns in physical activity and sedentary behaviour from mid-life to early old age: a substudy of the Whitehall II cohort. J Epidemiol Community Health. 2012;66(12):1110-5. https://doi.org/10.1136/jech-2011-200505.

85. Mark Cl, Fisher JA, Pike GB. Improved fMRI calibration: precisely controlled hyperoxic versus hypercapnic stimuli. Neuroimage. 2011;54(2):1102-11. https://doi.org/10.1016/j.neuroimage.2010.08.070.

86. Mazerolle EL, Ma Y, Sinclair D, Pike GB. Impact of abnormal cerebrovascular reactivity on BOLD fMRI: a preliminary investigation of moyamoya disease. Clin Physiol Funct Imaging. 2018;38(1):87-92. https://doi.org/10.1111/cpf.12387.

87. Downar J, Crawley AP, Mikulis DJ, Davis KD. The effect of task relevance on the cortical response to changes in visual and auditory stimuli: an eventrelated fMRI study. Neuroimage. 2001;14(6):1256-67. https://doi.org/10.1006/ nimg.2001.0946.

88. Buysse DJ, Reynolds CF, Monk TH, Berman SR, Kupfer DJ. The Pittsburgh Sleep Quality Index: a new instrument for psychiatric practice and research. Psychiatry Res. 1989;28(2):193-213. https://doi.org/10.1016/0165-1781 (89)90047-4

89. Ancoli-Israel S, Cole R, Alessi C, Chambers M, Moorcroft W, Pollak CP. The role of actigraphy in the study of sleep and circadian rhythms. Sleep. 2003; 26(3):342-92. https://doi.org/10.1093/sleep/26.3.342.

90. Anderson RT, Aaronson NK, Wilkin D. Critical review of the international assessments of health-related quality of life. Qual Life Res. 1993;2(6):369-95. https://doi.org/10.1007/BF00422215.

91. EuroQol Group. EuroQol - a new facility for the measurement of healthrelated quality of life. Health Policy (New York). 1990;16(3):199-208.

92. Herdman M, Gudex C, Lloyd A, Janssen M, Kind P, Parkin D, et al. Development and preliminary testing of the new five-level version of EQ-5D (EQ-5D-5L). Qual Life Res. 2011;20(10):1727-36. https://doi.org/10.1007/s1113 6-011-9903-X.

93. Xie F, Pullenayegum E, Gaebel K, Bansback N, Bryan S, Ohinmaa A, et al. A time trade-off-derived value set of the EQ-5D-5L for Canada. Med Care. 2016:54(1):98-105. https://doi.org/10.1097/MLR.0000000000000447.

94. Hecksteden A, Faude O, Meyer T, Donath L. How to construct, conduct and analyze an exercise training study? Front. Physiol. 2018;9:1007. https://doi. org/10.3389/fphys.2018.01007.

95. Stern Y, Lee S, Predovan D, Sloan RP. Sex moderates the effect of aerobic exercise on some aspects of cognition in cognitively intact younger and middle-age adults. J Clin Med. 2019;8(6):886.

96. Stern Y, Mackay-Brandt A, Lee S, McKinley P, Mclntyre K, Razlighi Q, et al. Effect of aerobic exercise on cognition in younger adults: a randomized clinical trial. Neurology. 2019;93(4):185.

97. Stothart CR, Simons DJ, Boot WR, Kramer AF. Is the effect of aerobic exercise on cognition a placebo effect? PLoS One. 2014;9(10):e109557. https://doi. org/10.1371/journal.pone.0109557.

\section{Publisher's Note}

Springer Nature remains neutral with regard to jurisdictional claims in published maps and institutional affiliations.

Ready to submit your research? Choose BMC and benefit from:

- fast, convenient online submission

- thorough peer review by experienced researchers in your field

- rapid publication on acceptance

- support for research data, including large and complex data types

- gold Open Access which fosters wider collaboration and increased citations

- maximum visibility for your research: over $100 \mathrm{M}$ website views per year

At BMC, research is always in progress.

Learn more biomedcentral.com/submissions 